\title{
Perception and Practice of Diabetic Patients about Hypoglycemia
}

Md. Jawadul Haque, ${ }^{1}$ Chinmoy Kanti Das, ${ }^{2}$ Md. Entekhab-Ul-Alam, ${ }^{3}$ Md. Nurul Amin, ${ }^{4}$ Jubaida Afroza Siddiqua, ${ }^{5}$ Farzana Hasan, ${ }^{6}$ Milon Kumar Haldar, ${ }^{7}$ Nelofar Yasmin, ${ }^{8}$ Shathi Kumar Rawson Kamal Md. Abu Syem Shah Amanath Ullah, ${ }^{9}$ Farhana Yasmin ${ }^{10}$

\section{ABSTRACT}

Background \& objective: Diabetes is major global epidemic with an ever-increasing trend. For diabetic patients hypoglycemia is a fact of life. The gravity of the problem demands that the diabetics must be aware about the symptoms of hypoglycemia as well as its immediate corrective measures to overcome the crisis. But, a substantial proportion of diabetic patients is unaware of all the symptoms of hypoglycemia leading to delayed management. This study was intended to assess the diabetic patients' perception about hypoglycemia.

Methods: The study was carried out in the Department of Community Medicine, Rajshahi Medical College, Rajshahi over a period of 2 months from April 2018 to May 2018. The diabetic patients in the rural area of Puthia Upazila were the respondents (study population). A total of 107 diabetic patients were consecutively included in the study. A self-administered questionnaire containing the variables of interest for evaluating perception of the respondents about diabetic hypoglycemia was used. Respondents' level of knowledge about hypoglycemia was measured using Likert Scale Score. Score ' 1 ' was assigned for each correct answer and score ' $O$ ' for each wrong answer. As there were more than one question in assessing respondents' level of knowledge, combined scores were used to measure respondents' perception about hypoglycemia.

Result: Over one-third (36.4\%) of the respondents was middle aged ( 40 - 50 years old) and $29 \%$ were upper middle aged ( $50-60$ years old) with mean age of the respondents being 51.3 years (range: $30-93$ years). Approximately $55 \%$ were male with male to female ratio being roughly 11:9 More than two-thirds of the respondents took measures to control diabetes and their compliance to treatment was also commendably high (83\%). The proportion of controlled diabetics was no less (57\%). But their knowledge about common symptoms and causes of hypoglycemia was poor (no more than $25 \%$ on an average). The knowledge about measures to be taken to correct hypoglycemia was even poor (no more than $20 \%$ on an average). The perception of the significance of symptoms of hypoglycemia and the importance of their correction were disappointingly low $(<10 \%)$. Overall half $(49.5 \%)$ of the respondents had very poor level of knowledge, over one-third $(34.6 \%)$ had poor knowledge, $13.1 \%$ had average knowledge and only $2.8 \%$ had good knowledge about symptoms of hypoglycaemia.

Conclusion: The study concluded that over two-thirds of the diabetic patients of Puthia Upazilla adopt measures to control diabetes and their compliance to treatment is appreciably high. The proportion of controlled diabetes is also appreciable. But their knowledge about symptoms, causes of hypoglycemia, measures to be taken to correct hypoglycemia and the importance of taking immediate measure to correct hypoglycemia are all inappreciably low.

Key words: Perception, practice, hypoglycemia, diabetic patients etc.

\section{Authors' information:}

' Dr. Md. Jawadul Haque, Professor \& Head, Department Community Medicine, Rajshahi Medical College, Rajshahi, Bangladesh.

${ }_{2}^{2}$ Prof. Dr. Chinmoy Kanti Das, Professor, Department of Community Medicine, Rajshahi Medical College, Rajshgahi.

${ }_{3}^{3}$ Dr. Md. Entekhab-UI-Alam, MBBS, DPH (DU), Assistant Professor, Department of Community Medicine, Rajshahi Medical College, Rajshgahi.

${ }^{4}$ Dr. Md. Nurul Amin, Assistant Professor, Department of Community Medicine, Rajshahi Medical College, Rajshahi \& Executive Editor, Ibrahim Cardiac Medical Journal, Ibrahim Cardiac Hospital \& Research Institute, Shahbag, Dhaka.

${ }^{5}$ Dr. Jubaida Afroza Siddiqua, Lecturer, Department of Community Medicine, Rajshahi Medical College, Rajshgahi.

${ }^{6}$ Dr. Farzana Hasan, Medical Officer, Department of Community Medicine, Rajshahi Medical College, Rajshgahi.

${ }^{7}$ Dr. Milon Kumar Haldar, Lecturer, Department of Community Medicine, Rajshahi Medical College, Rajshgahi.

${ }^{8}$ Dr. Nelofar Yasmin, Lecturer, Department of Community Medicine, Rajshahi Medical College, Rajshgahi.

${ }^{9}$ Dr. Shathi Kumar Rawson Kamal Md. Abu Syem Shah Amanath Ullah, Associate Professor, Institute of Health Technology, Rajshahi Medical College, Rajshahi.

${ }^{10}$ Dr. Farhana Yasmin, Lecturer, Department of Community Medicine, Rajshahi Medical College, Rajshgahi.

Correspondence: Dr. Md. Jawadul Haque, Phone: +8801730406553 E-mail: mjhaque59@yahoo.comcom 


\section{INTRODUCTION:}

Diabetes mellitus appears to be a global epidemic \& increasingly becoming a major non-communicable disease threatening both affluent and non-affluent society. More than 170 million people worldwide have diabetes, and this figure is projected to more than double by the year 2030, if the current trends continue further. ${ }^{1}$ For diabetic patients hypoglycemia is a fact of life. $^{2}$ There is now compelling evidence from the Diabetes Control and Complications Trial (DCCT), that good glycemic control delays the development and progression of retinopathy, neuropathy and nephropathy in IDDM (Insulin- dependent Diabetes Mellitus). However, maintenance of strict glycemic control may sometimes lead to hypoglycemia. ${ }^{3}$ Approximately $90 \%$ of all patients who receive insulin have experienced hypoglycemic episodes sometimes in their lives. The reported incidence of hypoglycemia varies considerably among studies; however in general patients with type 1 diabetes have an average of two episodes of sympotomatic hypoglycemia per week and one episode of severe hypoglycemia once a year. An estimated $2-4 \%$ death of this population have been attributed to hypoglycemia. ${ }^{4}$ These findings undoubtedly provide further impetus to patients and health care providers to attempt to maintain plasma glucose levels as close to the non-diabetics range as possible.

A cross-sectional study done on 20 outpatients having type 1 diabetes for at least 10 years revealed that hypoglycemia negatively affected their interpersonal relationship. ${ }^{5}$ A prospective observational study was conducted among 344 patients with type 2 diabetes mellitus to assess the risk factors for hypoglycemic episodes. Electronically recorded self-monitored blood glucose results were collected during 12 months of routine monitoring. Over half $(51.2 \%)$ of the subjects documented at least one hypoglycemic reading for a total of 1662 episodes; They attributed that hypoglycemia occurred due to missing a meal (53.3\%) orexercise $(23.8 \%)$. The study also showed that a high proportion of stable, insulin-treated subjects developed hypoglycemic episode. ${ }^{6}$ A prospective study conducted in Philadelphia on hypoglycemia in hospitalized diabetic patients receiving antihyperglycemic therapy showed that about $10 \%$ of them experienced 484 hypoglycemic episodes. Of these episodes, $72 \%$ were in patients receiving only insulin indicating hypoglycemia is common in hospitalized patients taking insulin. ${ }^{7}$

The gravity of the problem demands that the diabetics must be aware about the symptoms of hypoglycemia as well as the corrective measures that should be taken immediately to overcome the crisis. But, a substantial proportion of diabetic patients, for lack of health education, cannot recognize all the symptoms of hypoglycemia (e.g. dizziness, palpitation, sweating, nausea and vomiting, lack of concentration, visual impairment, abdominal discomfort, tremor, intense hunger, speech disabilities) ${ }^{8-10}$ and hence their proper management is delayed ${ }^{11}$. For this reason diabetic patients' perception about hypoglycemia needs to be assessed, which demands a formal study. The present study was, therefore, undertaken to assess the knowledge of diabetic patients about symptoms of hypoglycemia and the measures to be taken to overcome those symptoms.

\section{METHODS:}

This descriptive cross-sectional study was carried out in the Department of Community Medicine Rajshahi Medical College, Rajshahi over a period of 2 months from April 2018 to May 2018. During the period a total of the 1001 adult respondents from Puthia Upazila Rajshahi were interviewed for assessing the prevalence of non-communicable diseases (diabetes, hypertension) among them; of them 107(10.7\%) were found diabetic (diagnosed by registered physicians or diabetic centers), 246(24.6\%) were hypertensive, and the rest $648(64.7 \%)$ were free from either conditions. These 107 diabetic patients (sample for the present study) were selected as respondents for studying their demographic variables, control measures for diabetes, knowledge related variables about symptoms of hypoglycemia, opinion about measures to be taken when symptoms of hypoglycemia develop and practice of the respondents when symptoms of hypoglycemia manifested etc. Data were collected on by a structured questionnaire with the help of face to face interview with the respondents. A list of symptoms was presented to the respondents and were asked to encircle those symptoms that were manifested during episodes that they interpret as representing hypoglycemia. The list of symptoms in the questionnaire was based on previous 
work that were used to provide validation of the correct allocation of symptoms to either autonomic or neuroglycopenic groups. ${ }^{12,13}$ The key variables of interest were operationalized. Hypoglycemia was defined as a condition, which occurs when one's blood glucose level is lower than normal, usually less than 63 $\mathrm{mg} / \mathrm{dl}$. Or $3.5 \mathrm{mmol} / \mathrm{l} .{ }^{14}$ Diabetes referred to individuals suffering from hyperglycaemia (fasting blood glucose level $>126 \mathrm{mg} / \mathrm{dl}$ or random blood glucose level > 200 $\mathrm{mg} / \mathrm{dl}$ ) resulting from defects in insulin secretion, insulin action, or both. ${ }^{14}$ Knowledge, in the present study, meant for having familiarity with symptoms of hypoglycaemia. It refereed to the correct response of diabetic patients to the knowledge questionnaire about hypoglycaemia and its management.

The level of knowledge of the respondents about hypoglycemia was measured using Likert Scale Score. Score ' 1 ' was assigned for each correct answer and score ' 0 ' for each wrong answer. As there were more than one question in assessing respondents' level of knowledge, combined scores were used to measure respondents' perception about the topic. As stated the levels of knowledge were measured on a $0-4$ Likert Scale, where 0 meant 'very poor knowledge' and 4 meant 'Excellent knowledge' with 'poor' 1, 'average' 2, and 'good' 3 in between them. First the level of knowledge was assessed separately for responses against each question. Then all these knowledgerelated scores were added together to find an overall level of knowledge. As there were 10 knowledge-related questions with highest obtainable score being ' 10 ', we divided the scores obtained from the respondents, on a 0 - 4 Likert scale, into five categories: 1 ) Very poor or grossly dissatisfactory - when $0-2$ responses were correct, 2) Poor- from 3 - 4 responses were correct, 3) Average - from 5 - 6 responses were correct, 4) Good - from 7 - 8 responses were correct and 5) Excellent from 9 - 10 responses were correct.

Collected data were processed and analyzed with the help of software SPSS (Statistical Package for Social Sciences) version 17.0. Statistical analyses were done using descriptive statistics. The data presented in categorical scale were expressed as frequency and corresponding percentage, while the data presented on continuous scale were expressed as mean, median and standard deviation from the mean. The summarized data were presented in the form of table and charts with due statistical interpretation.

\section{RESULTS:}

Age distribution shows that over one-third (36.4\%) of the respondents was middle aged ( $40-50$ years old), $29 \%$ upper middle-aged (50-60 years old), $18.7 \%<40$ years and $6.5 \%>70$ years old. The mean age was 51.3 years and the youngest and the oldest patients were 30 and 93 years old respectively. Approximately 55\% were male with male to female ratio being roughly 11:9 (Table I). Majority $(90.7 \%)$ of the respondents was married. In terms of occupation, $14 \%$ were service-holder, $38.3 \%$ were housewife, $15 \%$ farmer, 29.9\% businessman (Table I). The average monthly income of the respondents was Taka 15537 (range: Taka 2000-40000). More than 40\% were primary level educated followed by illiterate $(24.3 \%)$, SSC $(17.8 \%)$, HSC $(10.3 \%)$ and graduate plus (4.7\%). Two-thirds $(67.3 \%)$ of the respondents were of normal BMI, $24.3 \%$ were overweight and $6.5 \%$ were obese (Fig. 1).

\begin{tabular}{|c|c|c|c|}
\hline $\begin{array}{l}\text { Demographic } \\
\text { characteristics }\end{array}$ & Frequency & Percentage & Mean \pm SD \\
\hline $\begin{array}{l}\text { Age }^{*} \text { (years) } \\
(30-93)\end{array}$ & & & $51.3 \pm 11.7$ \\
\hline$<40$ & 20 & 18.7 & -- \\
\hline $40-50$ & 39 & 36.4 & -- \\
\hline $50-60$ & 31 & 29.0 & -- \\
\hline $60-70$ & 10 & 9.3 & -- \\
\hline$>70$ & 7 & 6.5 & -- \\
\hline \multicolumn{4}{|l|}{ Sex } \\
\hline Male & 59 & 55 & -- \\
\hline Female & 48 & 45 & -- \\
\hline \multicolumn{4}{|l|}{ Marital status } \\
\hline Married & 97 & 90.7 & -- \\
\hline Unmarried & 4 & 3.7 & -- \\
\hline Divorced/widow & 6 & 5.6 & -- \\
\hline \multicolumn{4}{|l|}{ Occupation } \\
\hline Service & 15 & 14.0 & -- \\
\hline Housewife & 41 & 38.3 & -- \\
\hline Farmer & 16 & 15.0 & -- \\
\hline Business & 32 & 29.9 & -- \\
\hline Others & 3 & 2.8 & -- \\
\hline Income (Taka) & & & $\begin{array}{c}15537 \pm 9158 \\
(2000-40000)\end{array}$ \\
\hline \multicolumn{4}{|l|}{ Education } \\
\hline Illiterate & 26 & 24.3 & -- \\
\hline Primary & 45 & 42.1 & -- \\
\hline SSC & 19 & 17.7 & -- \\
\hline HSC & 11 & 10.3 & -- \\
\hline Graduate plus & 6 & 5.6 & -- \\
\hline
\end{tabular}




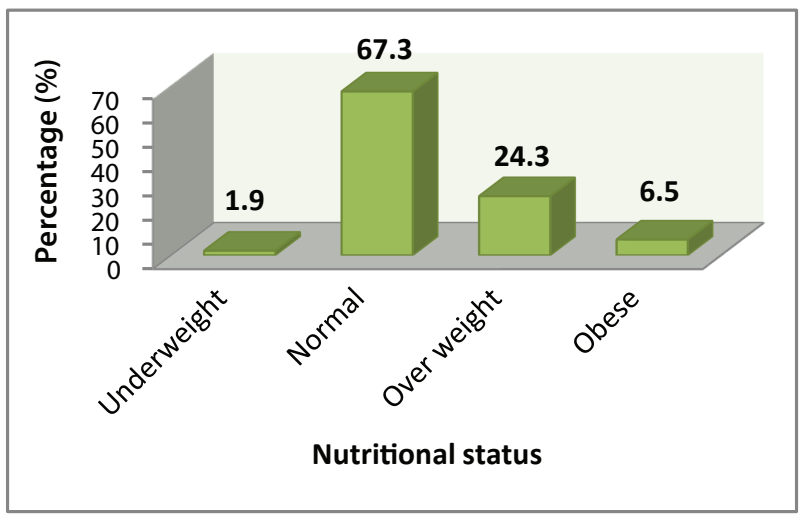

Fig. 1: Distribution of respondents by their nutritional status $(n=107)$

Majority $(93.7 \%)$ of the respondents was suffering from Type-II diabetes. The average duration of diabetes was 6 years and the shortest and longest durations were 1 and 25 years respectively (Table II). As measures of controlling diabetes, most ( $86 \%)$ of the respondents adopted diet control, $68.2 \%$ were used to using exercise. Over $70 \%$ were taking oral hypoglycemic agent \& $27.1 \%$ insulin as antidiabetic therapy. Majority (83.2\%) was complia to treatment of diabetes. Approximately $58 \%$ of the respondents had control over diabetes (Table III). The respondents' knowledge about symptoms of hypoglycemia are illustrated in table IV. Nausea and vomiting were mentioned by more than half $(55.1 \%)$ of the respondents followed by abdominal discomfort $(49.5 \%)$, slurring of speech $(31.8 \%)$, lack of concentration (30.8\%), blurring of vision (22.4\%), intense hunger $(21.5 \%)$, tremor of hands and feet $(20.6 \%)$, palpitation $(19.6 \%)$, sweating $(16.8 \%)$ and dizziness the least (6.5\%). Asked about the causes of hypoglycemia, around one-third told missed meal $(34.6 \%)$, over exercise $(33.6 \%)$ and overdose of insulin or oral hypoglycemic agent (35.5\%). About one-quarter $(23.4 \%)$ mentioned inadequate food intake and $13.1 \%$ told delay in taking food (Table V). As respondents were asked what could be done if symptoms of hypoglycaemia occur, over one-quarter (26.2\%) told blood sugar to be measured, $17.8 \%$ were in favour of taking light meal or snacks, $15 \%$ added to seek medical advice and $9.3 \%$ told sugar to be ingested (Table VI). Out of total respondents, only $15(14 \%)$ ever admitted in the hospital for hypoglycaemic episode. Of them $9(60 \%)$ experienced one episode of hypoglycaemia, $3(20 \%)$ 2-episodes, $2(13.3 \%) 3$-episodes and only $1(6 / 7 \%)$ 5-episodes (Table VII). Respondents stratified by their opinion about hypoglycaemia and importance of correction of hypoglycaemia are shown in Table VIII. Respondents' level of knowledge about symptoms of hypoglydcemia was categorised based on Likert scale as described earlier in the 'Methodology' section. Accordingly over half (49.5\%) of the respondents had very poor level of knowledge, over one-third (34.6\%) had poor knowledge, $13.1 \%$ had average knowledge and only $2.8 \%$ had good knowledge about symptoms of hypoglydcemia. None had excellent level of knowledge (Table IX).

\begin{tabular}{|c|c|c|c|}
\hline $\begin{array}{l}\text { Diabetes } \\
\text { related profile }\end{array}$ & Frequency & Percentage & Mean \pm SD \\
\hline \multicolumn{4}{|c|}{ Type of diabetes } \\
\hline Type I & 7 & 6.5 & -- \\
\hline Type II & 100 & 93.5 & -- \\
\hline
\end{tabular}

Duration of Diabetes

$--\quad 6.0 \pm 4.6(1-25)$

Table III. Respondents' distribution by diabetes control measure taken

\begin{tabular}{|c|c|c|}
\hline $\begin{array}{l}\text { Diabetes control } \\
\text { measures taken }\end{array}$ & Frequency & Percentage \\
\hline Diet control & 92 & 86.0 \\
\hline Regular exercise & 73 & 68.2 \\
\hline Oral hypoglycemic agent & 75 & 70.1 \\
\hline Insulin & 29 & 27.1 \\
\hline \multicolumn{3}{|c|}{ Reported compliance to treatment } \\
\hline Compliant & 89 & 83.2 \\
\hline Non-compliant & 18 & 16.8 \\
\hline \multicolumn{3}{|l|}{ Diabetes under control } \\
\hline Yes & 62 & 57.9 \\
\hline No & 17 & 15.9 \\
\hline Don't know & 28 & 26.2 \\
\hline
\end{tabular}




\begin{tabular}{|c|c|c|}
\hline Symptoms of hypoglycaemia & Frequency & Percentage \\
\hline \multicolumn{3}{|l|}{ Dizziness } \\
\hline Yes & 7 & 6.5 \\
\hline No / Don't know & $96 / 4$ & $89.7 / 3.7$ \\
\hline \multicolumn{3}{|l|}{ Palpitation } \\
\hline Yes & 21 & 19.6 \\
\hline No / Don't know & $73 / 13$ & $68.2 / 12.1$ \\
\hline \multicolumn{3}{|l|}{ Sweating } \\
\hline Yes & 18 & 16.8 \\
\hline No / Don't know & $77 / 12$ & $72.0 / 11.2$ \\
\hline \multicolumn{3}{|l|}{ Nausea \& vomiting } \\
\hline Yes & 59 & 55.1 \\
\hline No / Don't know & $37 / 11$ & $34.6 / 10.3$ \\
\hline \multicolumn{3}{|l|}{ Lack of concentration } \\
\hline Yes & 33 & 30.8 \\
\hline No / Don't know & $43 / 31$ & $40.2 / 29.0$ \\
\hline \multicolumn{3}{|l|}{ Blurring of vision } \\
\hline Yes & 24 & 22.4 \\
\hline No / Don't know & $73 / 10$ & $68.2 / 9.3$ \\
\hline \multicolumn{3}{|l|}{ Abdominal discomfort } \\
\hline Yes & 53 & 49.5 \\
\hline No / Don't know & $35 / 19$ & $32.7 / 17.8$ \\
\hline \multicolumn{3}{|l|}{ Tremor } \\
\hline Yes & 22 & 20.6 \\
\hline No / Don't know & $75 / 10$ & $70.1 / 9.3$ \\
\hline \multicolumn{3}{|l|}{ Intense hunger } \\
\hline Yes & 23 & 21.5 \\
\hline No / Don't know & $77 / 7$ & $72.0 / 6.5$ \\
\hline \multicolumn{3}{|l|}{ Slurring of speech } \\
\hline Yes & 34 & 31.8 \\
\hline No / Don't know & $51 / 22$ & $47.7 / 20.6$ \\
\hline
\end{tabular}

\begin{tabular}{|c|c|c|}
\hline Causes of hypoglycaemia & Frequency & Percentage \\
\hline \multicolumn{3}{|l|}{ Inadequate food intake } \\
\hline Yes & 25 & 23.4 \\
\hline No/Don't know & $50 / 32$ & $46.7 / 29.9$ \\
\hline \multicolumn{3}{|l|}{ Delay in taking food } \\
\hline Yes & 14 & 13.1 \\
\hline No / Don't know & $59 / 34$ & $55.1 / 31.8$ \\
\hline \multicolumn{3}{|l|}{ Missed meal } \\
\hline Yes & 37 & 34.6 \\
\hline No / Don't know & $35 / 35$ & $32.7 / 32.7$ \\
\hline \multicolumn{3}{|l|}{ Over exercise } \\
\hline Yes & 36 & 33.6 \\
\hline No / Don't know & $22 / 49$ & $20.6 / 45.8$ \\
\hline \multicolumn{3}{|l|}{ Overdose of insulin or OHA } \\
\hline Yes & 38 & 35.5 \\
\hline No / Don't know & $16 / 53$ & $15.0 / 49.5$ \\
\hline
\end{tabular}

Table VI. Knowledge about measures to be taken if symptoms of hypoglycemia occur

$\begin{array}{lcc}\text { Measures to be taken } & \text { Frequency } & \text { Percentage } \\ \begin{array}{l}\text { Sugar ingestion /Intake of CHO } \\ \text { Yes }\end{array} & 10 & \\ \quad \text { No / Don't know } & 68 / 29 & 6.3 \\ \text { Light meal / Snacks intake } & & \\ \quad \text { Yes } & 19 & 17.8 \\ \quad \text { No / Don't know } & 61 / 27 & 57.0 / 25.2 \\ \begin{array}{l}\text { Measure blood sugar } \\ \text { Yes }\end{array} & 28 & \\ \quad \text { No / Don't know } & 39 / 40 & 36.4 / 37.4 \\ \begin{array}{l}\text { Seek medical advice } \\ \text { Yes }\end{array} & 16 & 15.0 \\ \text { No / Don't know } & 68 / 23 & 63.6 / 21.5\end{array}$

Table VII. Distribution by hypoglycaemic episode related variables

$\begin{array}{lcc}\begin{array}{l}\text { Hypoglycaemic } \\ \text { episode related variables }\end{array} & \text { Frequency } & \text { Percentage } \\ \begin{array}{l}\text { Ever admitted to hospital } \\ \text { for hypoglycaemia }\end{array} & & \\ \quad \text { Yes } & 15 & 14.0 \\ \quad \text { No } & 92 & 86.0 \\ \text { How many times did } & & \\ \text { that happen (n=15) } & & \\ 1 & 9 & 60.0 \\ 2 & 3 & 20.0 \\ 3 & 2 & 13.3 \\ 5 & 1 & 6.7\end{array}$

Table VIII. Distribution respondents by opinion about hypoglycaemic and glycaemic control

\begin{tabular}{|c|c|c|}
\hline Opinion & Frequency & Percentage \\
\hline \multicolumn{3}{|l|}{$\begin{array}{l}\text { Perception of the symptoms } \\
\text { of hypoglycemia }\end{array}$} \\
\hline $\begin{array}{l}\text { Nothing serious } \\
\text { It may happen, but }\end{array}$ & 25 & 23.4 \\
\hline should be prevented & 44 & 41.1 \\
\hline $\begin{array}{l}\text { Very serious, it should } \\
\text { never happen }\end{array}$ & 29 & 27.1 \\
\hline Life-threatening emergency & 9 & 8.4 \\
\hline \multicolumn{3}{|l|}{$\begin{array}{l}\text { Importance of correction } \\
\text { of hypoglycaemia }\end{array}$} \\
\hline Not important & 7 & 6.5 \\
\hline Important but not so emergency & 17 & 15.9 \\
\hline Very important & 74 & 69.2 \\
\hline Urgent and life-saving measure & 9 & 8.4 \\
\hline
\end{tabular}


Table IX. Respondents' level of knowledge about hypoglycemia $(n=107)$

\section{Level of knowledge}

(Likert scale score)

\section{Frequency}

Very poor $(0-2)$

Poor (3 - 4)

Average (5-6)

Good (7 - 8)

Excellent $(9-10)$

\section{3}

37

14

03

00
Percentage

49.5

34.6

13.1

2.8

0.0

\section{DISCUSSION:}

In the present study nearly two-thirds (65.4\%) of the diabetics were middle-aged and nearly $60 \%$ were primary or secondary level educated. Majority $(93.7 \%)$ of the respondents was suffering from Type-II diabetes. El-zubier ${ }^{15}$ demonstrated that majority of subjects in their sample was beyond middle aged, of low level of literacy, and suffering from type 2 diabetes mellitus. The findings of the present study revealed that half $(49.5 \%)$ of the diabetics had very poor knowledge about symptoms of hypoglycemia, one-third (34.6\%) poor knowledge, $13.1 \%$ had average level of knowledge. Only $2.8 \%$ had good knowledge with none having excellent knowledge. Consistent with these findings, El-zubier's ${ }^{15}$ study revealed that only half of the diabetic subjects can recognize a few symptoms of hypoglycaemia.

The low level of perception about hypoglycaemia is common, even among medical staff ${ }^{16}$ and it reflects on the quality of care offered to diabetic patients. These findings can be partially explained by the fact that the major proportion of the sample is composed of subjects with low educational status. But equally important would be the problem of lack of health education and doctor-patient communication gap. ${ }^{17}$ Studies have shown that problem of inadequate knowledge about symptoms of hypoglycaemia is not uncommon as is found in Saudi Arabia ${ }^{18}$ as well as elsewhere in the world. ${ }^{19,9}$ Apart from directly leading to death, one of the indirect hazards of hypoglycaemia is that it may endanger the life of a diabetic patient, particularly if it occurs during a risky activity like motor car driving. ${ }^{20}$ Hypoglycaemia may cause many symptoms like dizziness, palpitation, sweating, nausea and vomiting, lack of concentration, loss of consciousness, abdominal discomfort, and intense hunger. In the present study the symptoms that are answered correctly by around $25 \%$ (average) of the patients were sweating, lack of concentration, slurring of speech \& tremor which are lower from those found in other studies. ${ }^{17,21}$ Hypoglycaemic episodes pose both acute and chronic risks. Transient hypoglycaemia can cause various acute cognitive-motor deficits ${ }^{22,24}$, which in turn can lead to industrial and automobile accidents \& fear \& embarrassment. ${ }^{24,25}$ Chronic cognitive-motor impairments have previously been reported after frequent severe hypoglycaemic episodes. ${ }^{26-28}$ It is, therefore, imperative that patients recognize hypoglycaemia early so that immediate corrective action can be taken. The importance of strict glycemic control to limit the risk of diabetic vascular complications is indisputable, but many barriers obstruct its attainment. Hypoglycemia is recognized to be a major limitation in achieving good control.

Subjective recognition of the symptoms of hypoglycaemia is fundamental to its effective self-management and to prevent its progression in severity. ${ }^{29}$ Symptoms are generated when arterial blood glucose concentrations is around 2.8-3.2 mmol/l (50-58 mg/dl) and in young adults have been classified as neuroglycopenic, autonomic, \& malaise. ${ }^{13}$ Hypoglycaemic symptoms are idiosyncratic and age specific. ${ }^{44}$ Recognition of low blood glucose is possible both through self-monitoring of blood glucose (SMBG) and detection of hypoglycaemic symptoms. SMBG is not a completely satisfactory method because it is performed too infrequently to recognize the rapid development of many hypoglycaemic episodes. The cognitive motor impairments associated with hypoglycaemia also may interfere with the accurate performance of SMBG. ${ }^{28}$

The present study, like any other scientific studies was not without limitations. The following 
limitations deserve mention:

1. The selection of study population was not based on stringent criteria. As type1 diabetics under insulin therapy are more prone to develop hypoglycaemia, inclusion of type1 diabetics alone could have better reflected perception of the diabetic patients about hypoglycaemia.

2. The study was done in a conveniently selected rural area, which may not reflect the actual situation of the entire rural areas in Bangladesh.

\section{CONCLUSION:}

The study concluded that over two-thirds of the diabetic patients of Puthia Upazilla take measures to control diabetes and their compliance to treatment is also appreciably high and proportion of controlled diabeticsis no less. But their knowledge about common symptoms and causes of hypoglycemia is poor (no more than $25 \%$ on an average). The knowledge about measures to be taken to correct hypoglycemia is even poor (no more than $20 \%$ on an average). The level of perception about symptoms of hypoglycemia and the importance of their correction are disappointingly low. As one in every seven patients suffered at least one episode of hypoglycemia since then they are suffering from diabetes, it highlights the importance of health education for diabetic subjects in order to make them able to recognize the symptoms of hypoglycemia and deal with it in an effective way.

\section{REFERENCES:}

1. Wild S, Roglic G, Green A, Sicree R, King H. Global prevalence of diabetes: estimates for the year 2000 and projections for 2030. Diabetes Care 2004;27(5): 1047-53.

2. Marshall SM, Home PD, Alberti KGMM, Krall LP, Cryer PE. Iatrogenic hypoglycemia in IDDM: Consequence, risk factors and prevention. In Diabetics annual. Eds Amsterdam elsvier 1993;7:317-31.

3. Hepburn DA, Deary IJ, Frier BM, Patrick AW, Quim JD, Fisher M. Symptoms of acute insulin induced Hypoglycemia in Humans with and without IDDM: factor analysis approach. Diabetes care 1991;14:949-57.
4. Cryer PE, Axelrod L, Grossman AB, Heller SR, Montori VM, Seaquist ER, et al., Evaluation and management of adult hypoglycemic disorders: an Endocrine Society Clinical Practice Guideline. J Clin Endocrinol Metab 2009 Mar;94(3):709-28. doi: 10.1210/jc.2008-1410. Epub 2008 Dec 16.

5. Ritholz MD, Jacobson AM. Living with hypoglycemia. J Gen Indren Med 1998;13(12):799-804,1497-1525.

6. Murata GH, Duckworth WC, Shah JH. Hypoglycemia in stable insuline treated Veterans with type 2 diabetes: a prospective study of 1662 episodes. Journal of Diabetes and Its Complications 2005;19(1):10-7.

7. Varghese P, Gleason V, Sorokin R. Hypoglycemia in hospitalized patients treated with antihyperglycaemic agents. J Hosp Med 2007;2(4):234-40.

8. Baomer AA, Elbushra HE. Profile of diabetic Omani pilgrims to Mecca. East Afr Med J 1998;75:211-14.

9. Bielefedt $\mathrm{K}$, Reis HE. Hypoglycaemia in type II diabetic patients. Med Kiln 1990;85:117-20.

10. Strauss G]. Hypoglycemia factors in intensive management of insulin depended diabetes mellitus. Nus Clin North Am 1996;735-45.

11. Guven M, Bayram F, Guven K, Kelestimur F. Evaluatio of patients admitted with Hypoglycaemia to a teaching hospital in central Anatolia. Postgrad Med J 2000;76: 150-52.

12. Hepburn DA, MacLeod KM, Pell ACH, Scougal IJ, Frier BM. Frequency \& symptoms of hypoglycaemia experienced by patients with type 2 diabetes treated with insulin. Diabet Med 1993;10:231-37.

13. Deary IJ, Hepburn DA, MacLeod KM, Frier BM. Partitioning the symptoms of hypoglycaemia using multi-sample confirmatory factor analysis. Diabetologia 1993;36: 771-77.

14. Frier B M, Fisher M, NR, Walker BR, Ralston HS. Diabetes mellitus. In: Colledge Davidson's principle \& practice of medicine. London Elsevier 2010;20:796-834.

15. Elizubier AG. Knowledge of Hypoglycemia by primary health care centers registered diabetic patients. Saudi Medical Journal 2001;22(3):219-22.

16. Piaggesi A, Bini L, Castro Lopez E, Giampietro O, Schipani E, Navalesi R. Knowledge on diabetes and performance among health professionals in nondiabetological departments. Acta Diabetol 1996;30:25-28.

17. Gillian T, Raffin TA. Physician virtues and communicating with patients. New Horiz 1997; 5:6-14.

18. Elzubier AG, Al-Amri AA, Al-Haraka E, Abu-Samara IO. Self-care, self-eliance and knowledge of diabetes 
among diabetics in Qassim Region. Saudi Arabia. Saudi Medical Journal 1996;17:598-603.

19. Ratzmann KP, Schimke E. Incidence of severe Hypoglycaemia in relation to metabolic control and patient knowledge. Med Klin 1995;90:557-61.

20. Schiel R, Ulbrich S, Muller UA. Quality of diabetes care, diabetes knowledge and risk of severe hypoglycaemia one and four years after participation in a 5-day structured treatment $\&$ teaching programme for intensified insulin therapy. Diabetes Metab 1998;24: 509-14.

21. Flanagan DE, Watson J, Everette J, Cavan D, Kerr D. Driving and insulin-consensus, conflict or confusion?. Diabet Med 2000;17:316-20.

22. Holmes CS, Hayford JT, Gonzalez JL, Weydert JA. A survey of cognitive functioning at different glucose levels in diabetic persons. Diabetes Care 1985;6: 180-85.

23. Pramming S, Thorsteinsson B, Stigsby B, Binder C. Glycaemic threshold for changes in electroencephalograms during hypoglycaemia in patients with insulin dependent diabetes. Br Med J 1988;296:665-67.

24. Stevens AB, McKane WR, Bell PM, Bell P, King DJ, Hayes JR. Psychomotor performance and counterregulatory responses during mild hypoglycemia in healthy volun- teers. Diabetes Care 1989;12:12-17.

25. Mehrotra R, Bajaj S, Kumar D, Singh KJ. Influence of education and occupation on knowledge about diabetes control. Natl Med J India 2000;13(6):293-6.

26. Wredling R, Levander S, Adamson U, Lins PE. Permanent neuropsychological impairment after recurrent episodes of severe hypoglycaemia in man. Diabetologia 1990;33:152-57.

27. Golden MP, Ingersoll GM, Brack CJ, Russell BA, Wright JC, Huberty TJ. Longitudinal relationship of asymptomatic hypoglycaemia to cognitive function in IDDM. Diabetes Care 1989;12:89-93.

28. Langan SJ, Deary IJ, Hepburn DA, Frier BM. Cumulative cognitive impairment following recurrent severe hypoglycaemia in adult patients with insulin-treated diabetes' Diabetelogia 1991;34:337-44.

29. Deary IJ. Symptoms of hypoglycaemia and effects on mental performance and emotions. In Hypoglycaemia in Clinical Diabetes. Frier BM, Fisher BM, Eds. Chichester, U.K., John Wiley and Sons 1999;29-54. 